Iranian Journal of Energy \& Environment Journal Homepage: www.ijee.net

IJEE an official peer review journal of Babol Noshirvani University of Technology, ISSN:2079-2115

\title{
Influence of Different Steam Cooling Techniques for High Pressure Turbine Blades on the Performance of Gas Turbine
}

\author{
T. C. Vadlamudi1*, R. Kommineni ${ }^{1}$, B. P. Katuru ${ }^{1}$, and N. K. N. Injeti ${ }^{2}$
}

${ }^{1}$ Department of Mechanical Engineering, R.V.R \& J.C College of Engineering, Guntur, India ${ }^{2}$ Department of Marine Engineering, A.U. College of Engineering, Visakhapatnam, India

\section{$P A P E R \quad I N F O$}

\section{Paper history:}

Received 31 July 2018

Accepted in revised form 24 Augest 2018

\section{Keywords:}

Gas turbine blade cooling

Internal convection cooling

Film and transpiration cooling

Irreversibility

Entropy generation rate

\section{$A \quad B \quad S T R A C T$}

Gas turbines are always intended to give more specific work output for which continuous exposure to hot combustion gases is necessary. To increase the lifespan of the turbine blades active cooling should be applied to the High Pressure (HP) turbine blades. In the present work, a simple open cycle gas turbine is modeled to carry out thermodynamic analysis with different open loop steam cooling techniques: steam internal convection cooling (SICC), steam film cooling (SFC) and steam transpiration (STC) cooling. The effect of Turbine inlet temperature (TIT), Turbine blade temperature $\left(\mathrm{T}_{\mathrm{b}}\right)$, and Compressor pressure ratio (CPR) on the coolant flow requirement and effect of $\mathrm{T} b$ on the performance were estimated. The entire analysis is carried out with contemplation of variable specific heat (VSH) along with constant specific heats (CSH) for air and gas. Between VSH and CSH approaches, the former analysis leads to better performance from the first and second law efficiencies point of view. Irreversibility and Entropy generation rate are maximum in the combustor and they are less for VSH case in all cooling schemes and are decreased by 38.540 and 40.4\% for SICC, SFC and STC schemes, respectively when compared with CSH (at TIT=1580K, $\mathrm{T}_{\mathrm{b}}=1123 \mathrm{~K}, \mathrm{CPR}=19.1$ ) analysis.

doi: 10.5829/ijee.2018.09.03.03

\section{INTRODUCTION}

Gas turbine finds wide applications because of its simplicity, reliability, and ease of operation. High-grade fuels such as natural gas and oil distillates are used in gas turbines. Methods are always strived to reduce specific fuel consumption because of the high cost of these fuels. In order to get maximum performance from gas turbines, it is always advised to operate at high Turbine Inlet Temperature (TIT) and high compressor pressure ratio (CPR) [1-3]. The operation of the turbine at such high temperatures would have an adverse effect on the reliability and service life of the gas turbine blades. An investigation on the reasons for the failure of HP turbine blades reveals that, as a result of continuous exposure to high-temperature gases, blades may be subjected to multiple failure mechanisms like hot corrosion, erosion, and fatigue $[4,5]$. From the review article on failure mechanisms of the HP turbine blades [6], it comes to know that, in order to have a longer life for the turbine blades, active cooling techniques should be provided for the stator and rotor blades of HP turbine. Louis et al. [7] have developed a consistent methodology to evaluate the performance of a simple open cycle gas turbine under the influence of different means of turbine blade cooling.
Singh and Prasad [8] have made a comparative study of the influence of different means of cooling on the performance of combined cycles. El-Masrihas [9] developed an interactive code for thermal analysis of gas turbine systems and also a model, for expansion in cooled turbines has been established [10].

Bolland and Stadaas [11] have made a comparative evaluation of combined cycles and gas turbine systems with the simple cycle, the steam-injected cycle, and the dual-recuperated intercooled after cooled steam-injected cycle (DRIASI cycle) with water injection, steam injection and recuperation. Sanjay et al. [12] have made a comparative study of the influence of different means of turbine blade cooling on the thermodynamic performance of combined cycle power plant. Sanjay Kumar and Onkar [13] have done a performance evaluation of gas-steam combined cycle having transpiration cooled gas turbine. Bassily [14] has developed a model with modifications of gas turbine cooling techniques for modern commercial combined cycle power plants by reducing the irreversibility of the HRSG. Polezhaev [15] has developed a transpiration cooling method for blades of the high-temperature gas turbine. Cooling gas effused through a porous wire mesh

* Corresponding author: Vadlam TaraChand

E-mail: tarachandvadlamudi@gmail.com 
skin will create an insulating film or boundary on the outer foil surfaces. This stagnant film layer will reduce the heat transfer from the gas to the coolant and hence power output can be increased. Faccinni and Stecco [16] have developed several mathematical-physical models for investigation of the effects of cooling on the cycle performance. The results show that first law and second law approaches are not alternatives but complementary in gaining insight into the thermodynamic effects of such cooling on the cycle. Facchini et al. [17] have made improvements in blade cooling techniques for the heavyduty gas turbine. The methods tried area reduction of air coolant temperature and the introduction of steam as cooling medium and also mixed steam/air cooling. The best results are obtained for an innovative closedopen/steam-air cooling system. Albeirutty et al. [18] have done heat transfer analysis for a multi-stage gas turbine using different open loop and closed loop blade cooling schemes. The results show that the combined system with closed loop steam cooling scheme gives better overall performance than does air cooling or the open circuit steam cooling. Najjar et al. [19] have made a comparative performance of combined cycle gas turbine systems under three different blade cooling schemes namely air-cooling, open-circuit steam cooling (OCSC) and closed-loop steam cooling (CLSC). Under the given conditions the power of the lower steam cycle with CLSC is increased by $6 \%$, accompanied by a $19 \%$ rise in cycle efficiency relative to OCSC at similar conditions. The CLSC results in $11 \%$ enhancement in power and $3.2 \%$ in efficiency relative to air-cooling. The CLSC is less sensitive to variations of operating variables at part load.

The current study is majorly aimed at parametric analysis of simple gas turbine power plant with a comparative study of energy and exergy efficiency with three open loop steam cooling schemes namely SICC, SFC, and STC under the two approaches. (a) Analysis with variable specific heat (VSH), (b) Analysis with constant specific heats $(\mathrm{CSH})$ for air and gas. The present work mainly focused to know:

The influence of operating parameters TIT, CPR and $\mathrm{T}_{\mathrm{b}}$ on the coolant flow requirement for HP turbine blades. The influence of $\mathrm{T}_{\mathrm{b}}$ on the performance of $\mathrm{a}$ simple gas turbine plant from the perspective of first law and second law efficiencies and specific work output .

Assessing the irreversibility and entropy generation rate across different components of a simple gas turbine plant. Comparison between VSH and CSH approaches for the entire analysis.

\section{MATERIAL AND METHOD}

Thermodynamic model of simple gas turbine cycle plant with open loop steam cooling schemes

Best cooling scheme for HP turbine blades improves the performance and needs less coolant requirement. The steam which is produced from the waste heat in the exhaust gases from the LP turbine is used as a coolant and is used to cool both the stator and rotor blades of the HP turbine .

Three open loop cooling schemes namely steam internal convection, steam film and steam transpiration cooling schemes as shown in Figure 1 are considered in this analysis. The amount of coolant requirement depends on the cooling technique employed. Figure 2 shows a flow diagram of a gas turbine consisting of a gas generator and power turbine mounted on two separate shafts. It includes an axial flow compressor consisting of 16 stages and gas generator (HP) turbine consisting of two stages and power (LP) turbine consisting of 6 stages. The high-temperature exhaust gases from the exit of HP turbine directly expand in the LP turbine. The thermodynamic state points are illustrated on Temperature - entropy diagram in Figure 3.

\section{Thermodynamic analysis of simple gas turbine with open loop steam cooling schemes}

The assumptions/input data used in the present analysis is given in Table 1 . The values of various parameters are taken from the existing literature and GE gas turbine handbook.
(a) Energy analysis
Compressor
The work equation is:

$$
\dot{W}_{i}=\dot{M}_{i} C_{p i} \Delta T_{i}
$$

$\mathrm{The} \Delta \mathrm{T}$ iis computed from the inlet of stage temperature $\mathrm{T} \_\mathrm{i}$ and the stage inlet and outlet pressuresP_i andP_(i+1), with the following equation.

$$
\frac{\Delta T_{i}}{T_{i}}=\left[\frac{P_{i+1}}{P_{i}}\right]^{\left(\frac{R}{\eta_{p c} C_{p a}}\right)}
$$

Mass balance and energy balance across the control volume of compressor gives,

$$
\begin{gathered}
\dot{m}_{c, i}=\dot{m}_{c, e}+\sum \dot{m}_{c, j} \\
\dot{W}_{C}=\dot{m}_{c, e} C_{P_{c, e}} T_{c, e}+\sum \dot{m}_{c, j} C_{P_{c, j}} T_{c, j} \\
-\dot{m}_{c, i} C_{P_{c, i}} T_{c, i}
\end{gathered}
$$

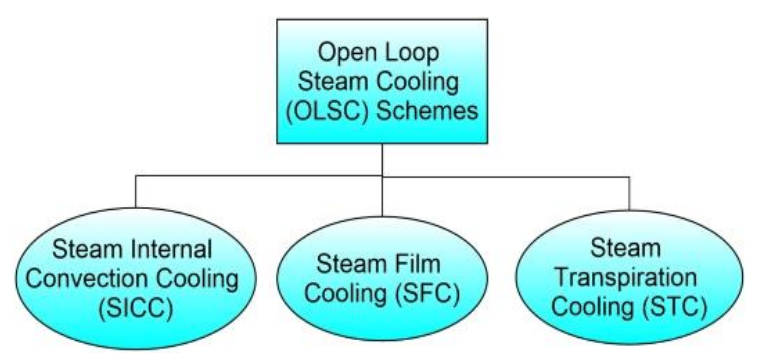

Figure 1. Open Loop Steam Cooling Schemes 


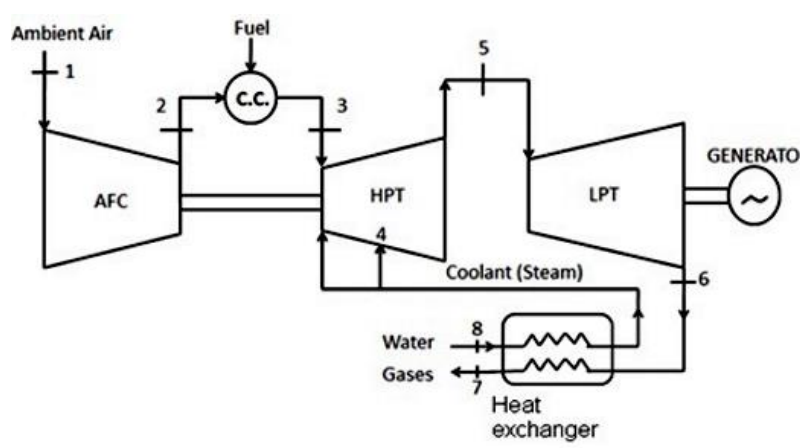

Figure 2. Schematic of steam cooled gas turbine model

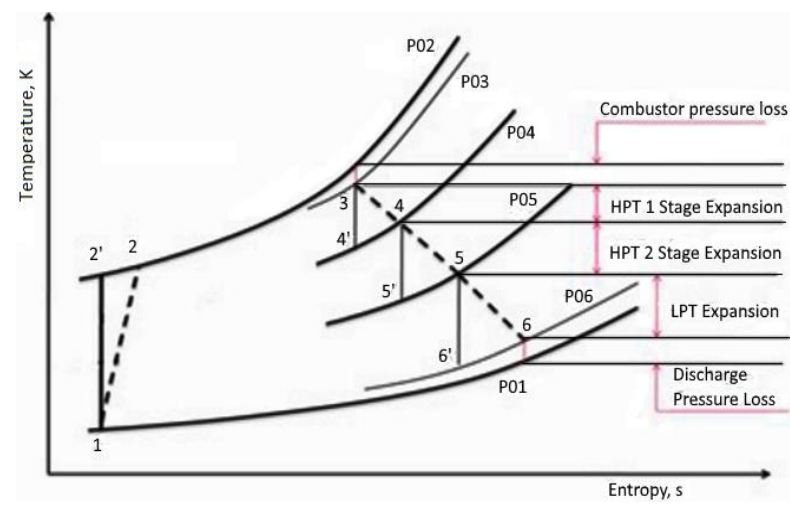

Figure 3. Temperature-Entropy diagram of the gas turbine model

TABLE 1. Assumptions/input data for the analysis

\begin{tabular}{lc}
\hline Parameters & Value \\
\hline Power of HP Turbine, PHPT & $29 \mathrm{MW}$ \\
Power of LP Turbine, PLPT & $23.2 \mathrm{MW}$ \\
HP Turbine Inlet Temperature, TIT & $1580 \mathrm{~K}$ \\
Pressure ratio, $r_{\mathrm{P}}$ & 19.1 \\
Air inlet pressure to compressor, $P_{1}=P_{01}$ & $1.013 \mathrm{bar}$ \\
Air inlet temperature to compressor , $T_{1}=T_{01}$ & $288 \mathrm{~K}$ \\
Combustion efficiency,$\eta_{\text {comb }}$ & $99.5 \%$ \\
Fuel used & Natural gas \\
Lower Heating Value & $42000 \mathrm{~kJ} / \mathrm{kg}$ \\
Isentropic efficiency of Compressor, $\eta_{\mathrm{c}}$ & 0.85 \\
Isentropic efficiency of turbine, $\eta_{\mathrm{t}}$ & 0.90 \\
Polytropic efficiency of compressor,$\eta_{\mathrm{PC}}$ & 0.92 \\
Polytropic efficiency of HP turbine, $\eta_{\mathrm{HPT}}$ & 0.92 \\
Polytropic efficiency of LP turbine, $\eta_{\mathrm{LPT}}$ & 0.92 \\
Maximum turbine blade temperature, $T_{b}$ & $1123 \mathrm{~K}$ \\
Auxiliary power required per $100 \mathrm{~kg} / \mathrm{s}$ of & $200 \mathrm{~kW}$ \\
compressor air & \\
\hline
\end{tabular}

\section{Combustor}

The combustion equation can be written as:

$$
\begin{aligned}
\lambda \mathrm{CH}_{4}+\left(0.21 \mathrm{O}_{2}+\right. & \left.0.79 \mathrm{~N}_{2}\right) \\
& \rightarrow(1+\lambda)\left[x_{\mathrm{CO}_{2}} \mathrm{CO}_{2}+x_{\mathrm{H}_{2} \mathrm{O}} \mathrm{H}_{2} \mathrm{O}\right. \\
& \left.+x_{\mathrm{O}_{2}} \mathrm{O}_{2}+x_{\mathrm{N}_{2}} \mathrm{~N}_{2}\right]
\end{aligned}
$$

where $\lambda$ is the fuel-air ratio. The mole fractions of gases leaving the combustion chamber are obtained from:

$$
\begin{aligned}
x_{\mathrm{CO}_{2}}=\frac{\lambda}{1+\lambda}, x_{\mathrm{H}_{2} \mathrm{O}} & =\frac{2 \lambda}{1+\lambda}, x_{O_{2}} \\
& =\frac{0.21-2 \lambda}{1+\lambda}, x_{N_{2}}=\frac{0.79}{1+\lambda}
\end{aligned}
$$

The specific heat of a mixture of gasses is expressed as the summation of the product of specific heat and mole fraction $\mathrm{x} \_\mathrm{i}$ of each component.

$$
c_{p}=\frac{1}{M_{p}} \sum_{i=1}^{n} x_{i} \bar{c}_{p i}
$$

and $\mathrm{M}_{\mathrm{p}}$ is the average molecular-weight of gas, which is given as

$$
M_{p}=\sum_{i=1}^{n} x_{i} M_{i}
$$

where $\mathrm{M}_{\mathrm{i}}$ is molecular weight of component ' $\mathrm{i}$.'

The mass balance for acombustor is given as under:

$$
\left(\dot{m}_{e}\right)_{c o m b}=\left(\dot{m}_{i}+\dot{m}_{f}\right)_{c o m b}
$$

\section{Cooled gas turbine}

In the open loop cooling schemes, the coolant passes through the internal drilled holes/ passages provides sufficient cooling to the blades. The coolant after cooling the blades of a stage mixes with hot expanding gases. The mixing of coolant with hot gases results in cooling losses, mixing and pumping losses, because of which there is a decrease in enthalpy and hence temperature and pressure also, after the stage. The model of expansion in a twostage steam cooled HP gas turbine including lossesis shown in Figure 4.

The following assumptions are made for the model:

(i) Conventionality internal cooled blades are considered as heat exchangers working at fixed blade temperature and an exit temperature of the coolant is expressed as a function of heat exchanger effectiveness as suggested by Louis et al., [7] Bolland and Stadaas [11], Singh and Prasad [8] and Harlock, et al. [ 21]

(ii) Isothermal effectiveness [7] as defined by the following equation is used for film and transpiration cooling concepts, which accounts for the reduced heat transfer from the gas to the blade. It can be defined as the ratio of the heat flux difference without and with film cooling to the heat flux without cooling to an isothermal wall. 


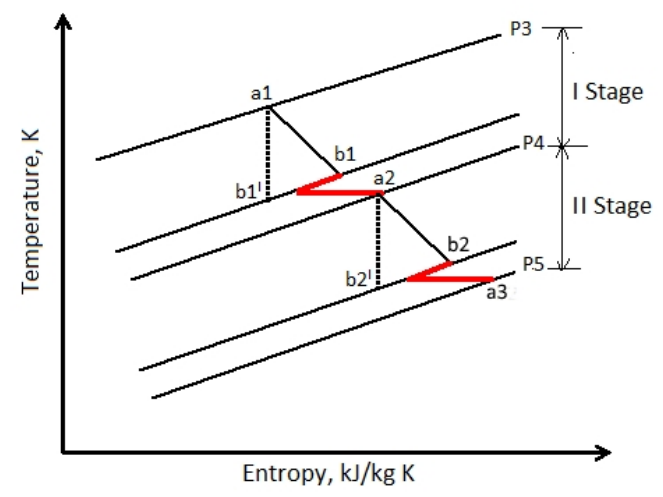

Figure 4. Model for expansion in a two-stage HP turbine with cooling and mixing losses

(i) Transpiration cooling takes a higher value of $\eta_{\text {iso }}$ when comparted with film cooling

(ii) For internal convection cooling $\eta_{\text {iso }}=0$

$$
\eta_{i s o}=\frac{q_{o}-q_{c}}{q_{0}}
$$

\section{Steam internal convection cooling (SICC)}

In this system, elaborate holes are made on the internal passages of the blades and the coolant after taking a number of turns finally comes out of the blade tip. The gas turbine blade parameters used in this analysis are given in Table 2.

The Cooling factor R_convcan be written as,

$$
R_{\text {conv }}=\frac{\left(T_{g i}-T_{b}\right) C_{p g}}{\varepsilon\left(T_{b}-T_{c i}\right) C_{\text {pteam }}}
$$

Heat exchanger effectiveness $\varepsilon$ can be defined as,

$$
\varepsilon=\frac{T_{c e}-T_{c i}}{T_{b}-T_{c i}}
$$

Coolant flow rate requirement in a blade row is given by following expression:

$$
\begin{array}{r}
\frac{\dot{m}_{c}}{\dot{m}_{g}}=S t_{g}\left[\left(\frac{S_{g}}{t \cos \alpha}\right) F_{s a}\right]\left[R_{c o n v}\right] \\
=0.0158 R_{c o n v}
\end{array}
$$

TABLE 2. Cooled gas turbine blade parameters

\begin{tabular}{lc}
\hline Parameter & Value \\
\hline Average Stanton Number, $\mathrm{St}_{\mathrm{g}}$ & 0.005 \\
Correction factor to account blade surface, $\mathrm{F}_{\mathrm{sa}}$ & 1.05 \\
Turbine blade geometry parameter, $\frac{\mathrm{s}_{\mathrm{g}}}{\operatorname{tcos} \alpha}$ & 2.86 \\
Isothermal effectiveness for film cooling, $\left(\eta_{\text {iso }}\right)_{\text {film }}$ & 0.5 \\
Isothermal effectiveness for transpiration & 0.75 \\
cooling, $\left(\eta_{\text {iso }}\right)_{\text {trans }}$ & $1123 \mathrm{~K}$ \\
\hline Turbine blade temperature, $\mathrm{T}_{\mathrm{b}}$ & \\
\hline
\end{tabular}

\section{Steam film cooling (SFC)}

In this system, the coolant flows internally in the counterflow direction of the blade contour and after taking sufficient heat finally ejects out from the leading edge and forms a thin blanket of the stagnant layer (film) over the blade outer surface which reduces heat transfer from the gas to the blade. Thus, in this case, the cooling is due to the joint action of internal convection and film formed over the surface and hence it's film cooling. The cooling factor is expressed as,

$$
R_{f i l m}=\frac{\left(T_{g i}-T_{b}\right) \mathrm{c}_{\mathrm{pg}}\left(1-\left(\eta_{\text {iso }}\right)_{\text {film }}\right)}{\varepsilon\left(T_{b}-T_{c i}\right) c_{\text {psteam }}}
$$

Thus the cooling requirement for film cooling scheme is expressed as,

$$
\frac{\dot{m}_{c}}{\dot{m}_{g}}=S t_{g}\left[\left(\frac{S_{g}}{t \cos \alpha}\right) F_{s a}\right]\left[R_{\text {film }}\right]=0.0158 R_{\text {film }}
$$

\section{Steamtranspiration cooling (STC)}

In this system of cooling, the blades are made with a porous material and several small holes are provided on the surface of the blades through which the coolant comes out after providing internal cooling as the previous case and forms an effective thick blanket of film over the blade surface which reduces the heat transfer from the gas to the internal coolant. Hence it is the most effective way among all the three schemes.

The cooling factor is expressed as,

$$
R_{\text {trans }}=\frac{\left(T_{g i}-T_{b}\right) \mathrm{c}_{\mathrm{pg}}\left(1-\left(\eta_{\text {iso }}\right)_{\text {trans }}\right)}{\varepsilon\left(T_{b}-T_{c i}\right) c_{\text {psteam }}}
$$

Thus the cooling requirement for Transpiration cooling scheme is expressed as follows:

$$
\frac{\dot{m}_{c}}{\dot{m}_{g}}=S t_{g}\left[\left(\frac{S_{g}}{t \cos \alpha}\right) F_{s a}\right]\left[R_{\text {trans }}\right]=0.0158 R_{\text {trans }}
$$

(b) Exergy Analysis

First and Second laws of thermodynamics applied to a cooled gas turbine lead to exergy balance equation as given by following expression:

$$
\dot{E} x_{Q}+\sum_{i} E x_{i}=\sum_{\mathrm{e}} \dot{E} x_{\mathrm{e}}+\dot{E} x_{w}+\dot{I}
$$

Here subscripts $\mathrm{i}$,e refers to the inlet and exit of the control volume, $(\mathrm{Ex})^{*}$ represents exergy and (I ) is Irreversibility or Exergy destruction rate.

The Exergy destruction rate or Irreversibility can be calculated from Eq. 19

$$
\dot{I}=T_{0} \dot{S}_{g e n}
$$

Exergy of fuel can be expressed as follows:

$$
e x_{f}=\xi \times L H V_{f}
$$

The hydrocarbon fuels $\left(\mathrm{C}_{\mathrm{j}} \mathrm{H}_{\mathrm{k}}\right)$ specific chemical exergy is approximated as follows [24]:

$$
\xi=\left(1.033+0.0169 \frac{k}{j}-\frac{0.0698}{j}\right)
$$




\section{Performance parameters}

Specific work output in $\mathrm{kJ} / \mathrm{kg}$ is given by Eq. 22 $W_{s p}=\frac{\dot{W}_{\text {net }}}{\dot{m}_{a}}$

Specific fuel consumption in $\mathrm{kg} / \mathrm{kWh}$ is given by Eq. 23

$$
\text { sfc }=\frac{m_{f}}{W_{\text {net }}}
$$

First law efficiency is given as follows:

$$
\eta_{I}=\left[\frac{\dot{W}_{\text {net }}}{\dot{m}_{f} L H V_{f}}\right]
$$

Second law efficiency is given by Eq. 25

$$
\eta_{I I}=\left[\frac{\dot{W}_{n e t}}{\dot{m}_{f} \times e x_{f}}\right]
$$

\section{RESULTS AND DISCUSSION}

The results of the parametric study to find the effect of operating parameters Turbine inlet temperature (TIT), Compressor pressure ratio (CPR) and Turbine blade temperature $\left(\mathrm{T}_{\mathrm{b}}\right)$ on the coolant flow requirement for $\mathrm{a}$ simple gas turbine is evaluated and plotted. The range of values for parameters used in these plots is taken from the existing literature. The performance characteristics first law, second law efficiencies and specific work output variation with the blade temperature also evaluated and plotted. Component wise Entropy generation rate and hence Irreversibility of a cooled gas turbine were also assessed for the above mentioned steam cooling methods, with both VSH and CSH approaches. Figure 5 shows the effect of TIT on coolant flow requirement for various open loop steam cooling schemes SICC, SFC, and STCfor maximum allowable turbine blade surface temperature $T_{b} 1123 \mathrm{~K}$ with CPR 19.1. From the plots, it is revealed that as TIT increases coolant requirement increases, for all cooling schemes. The minimum coolant requirement is found to be in the case of STC with constant specific heat analysis. Transpiration cooling provides reduced heat transfer because of a large number of holes in blades through which coolant passes and forms a film of coolant serving as athermal barrier for hot gas. The maximum cooling requirement is found in the case of SICC and it increases faster with an increase in TIT as compared to other cooling schemes because of more heat transfer from the gases to the coolant. Among the three cooling schemes, STC is the best cooling option followed by SFC and SICC. Like STC, in SFC also coolant film is provided on the blade surface which acts as athermal barrier for the hot gas. It is also observed from the plots that for all the cooling schemes the requirement of coolant slightly increases in the case of VSH analysis when compared with $\mathrm{CSH}$ analysis because of slightly increased heat transfer rates with VSH approach.

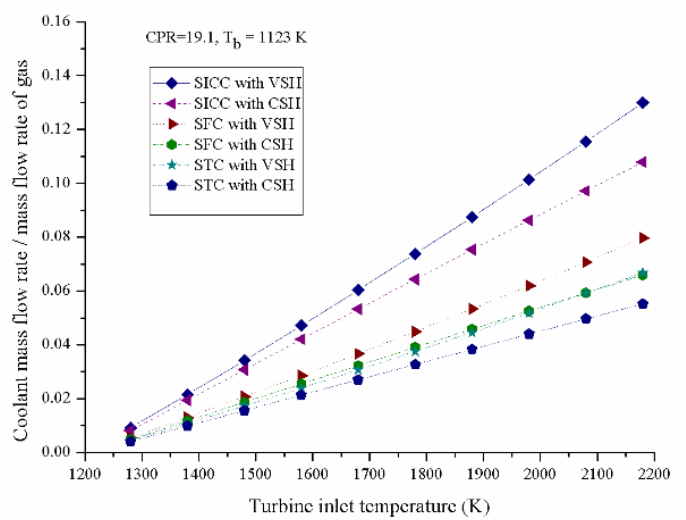

Figure 5. Effect of TIT on coolant mass flow rate for different open loop steam cooling schemes SICC, SFC and STC

Figure 6 shows the coolant flow requirement for different open loop steam cooling schemes SICC, SFC, and STC with respect to $\mathrm{CPR}$ at TIT $1580 \mathrm{~K}$ and maximum allowable turbine blade temperature T_b 1123K. Here also STC and SFC schemes have least coolant requirement when compared with SICC. The effect of CPR is less when compared with TIT. It is observed that coolant flow rate variation with change in CPR for SFC and STC is insignificant whereas for SICC it is substantial because of more heat transfer in SICC when compared with the remaining two schemes .

Figure 7 shows the coolant flow requirement with respect to turbine blade temperature for different open loop steam cooling schemes for design parameters of CPR 19.1 and TIT $1580 \mathrm{~K}$. From the plots, it shows that all steam cooling schemes have reduced coolant requirement when the blade temperature increases from $1100 \mathrm{~K}$ to $1450 \mathrm{~K}$. The reason for this trend is, as blade temperature increases cooling factor decreases and hence coolant requirement also decreases for all cooling schemes. Here also the cooling requirement decreases starting from SICC to SFC to STC. The coolant requirement increases for $\mathrm{VSH}$ analysis when compared with CSH analysis for all cooling schemes.

Figures 8 show the effect of maximum allowable turbine blade temperature on specific work output for a given condition of CPR 19.1 and TIT $1580 \mathrm{~K}$ for different open loop steam cooling schemes. From the plot, it is observed that as allowable turbine blade temperature increases the specific work output continuously increases up to the blade temperature of $1450 \mathrm{~K}$ for all steam cooling schemes. The reason for this trend is because of the fact that due to the lower temperature difference between TIT and T_b when T_b is increased, less heat transfer takes place to the coolant and hence more energy 


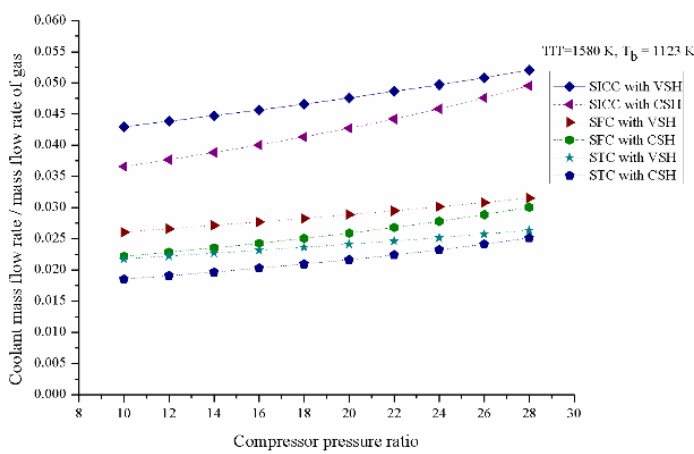

Figure 6. Effect of CPR on coolant mass flow rate for different open loop steam cooling schemes SICC, SFC, and STC

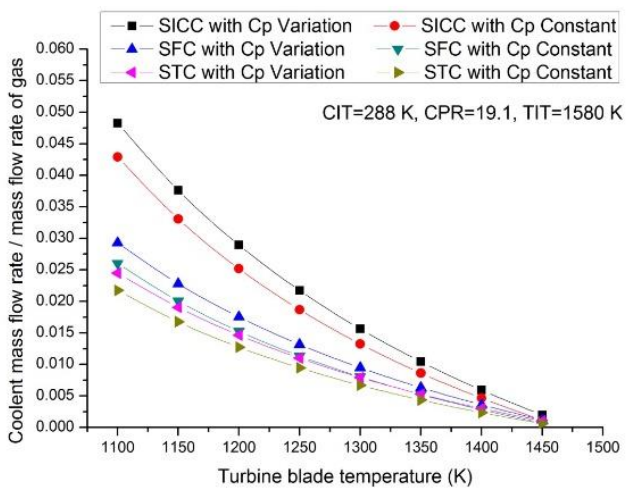

Figure 7. Effect of Turbine blade temperature $(\mathrm{Tb})$ on the coolant mass flow rate for different open loop steam cooling schemes SICC, SFC, and STC

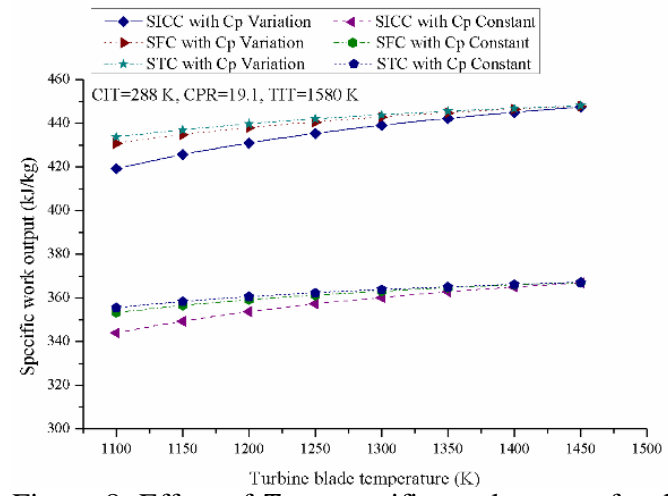

Figure 8. Effect of $T_{b}$ on specific work output for different open loop steam cooling schemes SICC, SFC, and STC

is available for producing work in HP turbine and merely one or two rows of blades need cooling. So turbine work increases and hence specific power output increases .

Figures 9 and 10 show the effect of maximum allowable turbine blade temperature on first law andsecond law efficiencies respectively for a given condition of CPR 19.1 and TIT $1580 \mathrm{~K}$ for different open loop steam cooling schemes. The performance characteristics first law and second law efficiencies continuously increase noticeably, as the turbine blade temperature increases for all the steam cooled schemes up to maximum blade temperature of $1450 \mathrm{~K}$, for both CSH and VSH analyses. The variation of first law and second law efficiencies with respect to blade temperature is marginal for SFC and STC schemes. For SICC significant variation is observed. But it shows improved values for VSH analysis when compared with $\mathrm{CSH}$ analysisat each turbine blade temperature. Being constant heat supplied, both efficiencies tend to increase because of increased specific work output with turbine blade temperature $\left(\mathrm{T}_{\mathrm{b}}\right)$.

Figures 11 and 12 show the Entropy generation rate and Irreversibility of various components ofthe cooled gas turbine (at CPR 19.1, $\mathrm{T}_{\mathrm{b}} 1123 \mathrm{~K}$ and TIT $1580 \mathrm{~K}$ ) for both $\mathrm{CSH}$ andVSH analyses. The entropy generation rate and hence irreversibilityis lower for all components in the case of VSH analysis when compared with CSH analysis. From the plots, it is observed that maximum Irreversibility and Entropy generation rate occurs in the combustion chamber due to combustion phenomena whichis highly irreversible. The irreversibilities of both HP and LP turbines show lower values when compared with the compressor. Minimum irreversibility is found in the STC scheme and highest is found in SICC scheme.

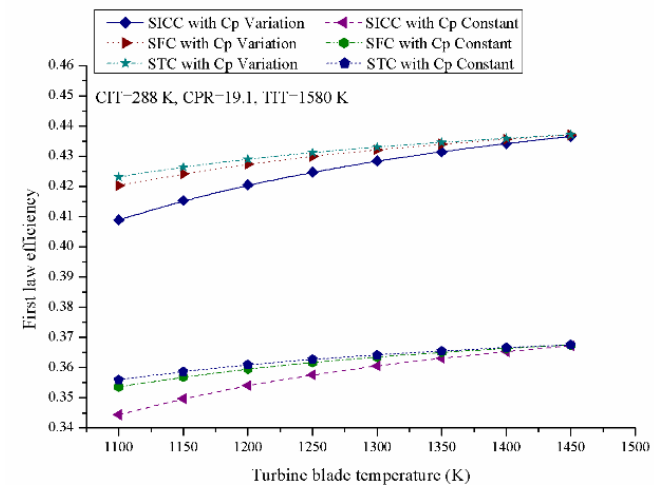

Figure 9. Effect of $T_{b}$ on first law efficiency for different open loop steam cooling schemes SICC, SFC and STC

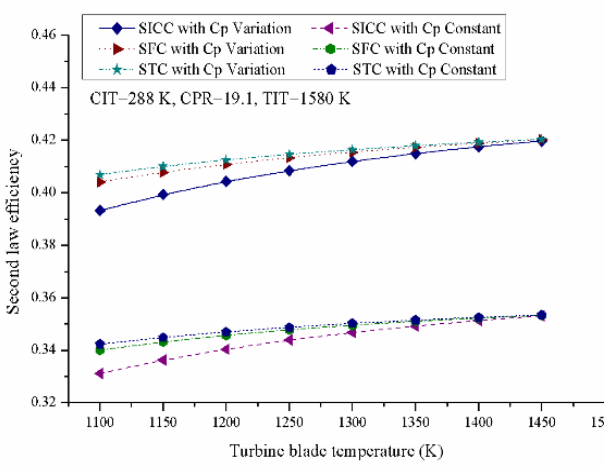

Figure 10. Effect of $\mathrm{T}_{\mathrm{b}}$ on second law efficiency for different open loop steam cooling schemes SICC, SFC, and STC 


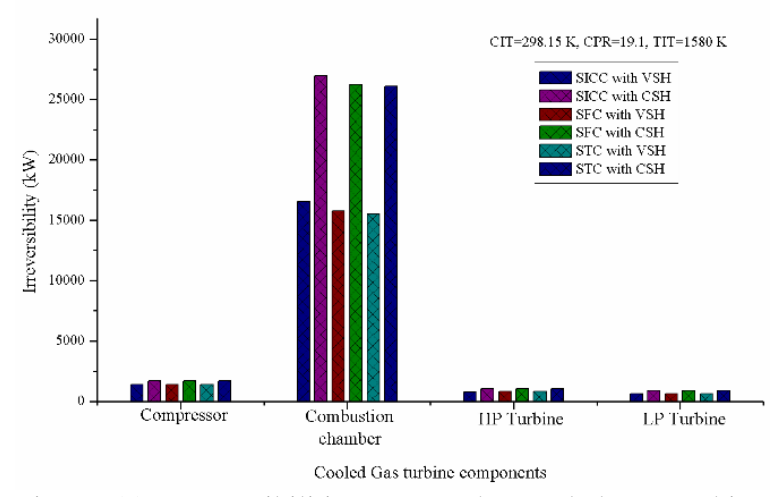

Figure 11. Irreversibilities across the cooled gas turbine components for different open loop steam cooling schemes SICC, SFC, and STC

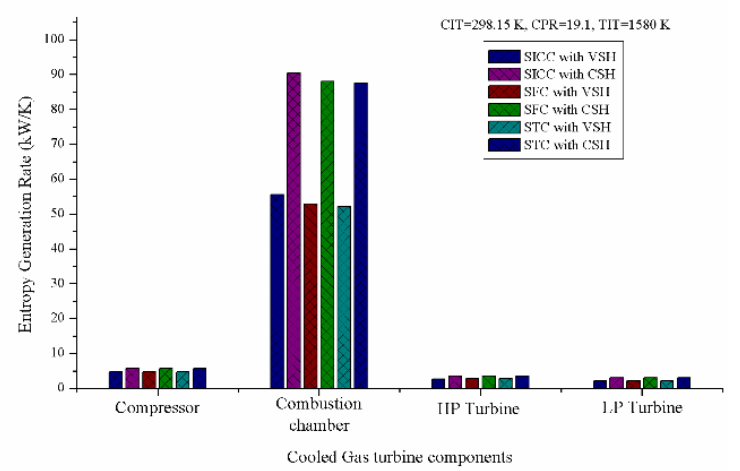

Figure 12. Entropy generation rate across cooled gas turbine components for different open loop steam cooling schemes SICC, SFC, and STC

\section{CONCLUSIONS}

In this work, the main attention is focused on making a comparison between different open loop steam cooling schemes SICC, SFC, and STC on the performance of the cooled gas turbine plant with CSH and VSH analyses. From the results, the following conclusions have been drawn. Among all the open loop steam cooling schemes considered, STC and SICC cooling schemes offer the minimum and maximum coolant flow requirement respectively. The coolant requirement for SFC scheme is in between SICC and STC schemes. The coolant requirement is slightly more in the case of VSH analysis when compared with CSH analysis for all cooling schemes. TIT is a more predominant factor in deciding the coolant requirement when compared with CPR. The coolant requirement drastically decreases with respect to an increase in turbine blade temperature from 1100 to $1450 \mathrm{~K}$ and attains minimum value at $\mathrm{T} \_\mathrm{b}=1450 \mathrm{~K}$. The First law efficiency, Specific work output, and Second law efficiency increases with allowable blade temperature and reaches a maximum value at T_ $b=1400 \mathrm{~K}$ for a fixed value of TIT for all cooling schemes. However, increasing trends are significantin the case of SICC when compared with remaining schemes. First law efficiency, Second law efficiency and Specific work output all have higher values for VSH analysis when compared with CSH analysis. Entropy generation rate and Irreversibility is maximum for the combustion chamber and decreases in the order of HP turbine followed by LP turbine. The entropy generation rate and hence irreversibility is lower for all components in the case of VSH analysis when compared with CSH analysis. It is concluded from the present analysis that, out of all open loop steam cooling schemes, STC scheme is preferable one with maximum performance and least coolant requirement. The VSH analysis gives the most realistic approach in evaluating the performance and yields better results with least irreversibility and entropy generation rates across all the components of a cooled gas turbine when compared with CSH analysis.

\section{REFERENCES}

1. Hüseyin Kurt, ZiyaddinRecebli and EnginGedik, 2008. Performance Analysis of Open Cycle Gas Turbines, Int. J. Energy Res., 33: 285-294. doi:10.1002/er.1472

2. M. M. Rahman, Thamir K. Ibrahim1 and Ahmed N. Abdalla, 2011. Thermodynamic Performance Analysis of Gas Turbine Power Plant, Int. J. Phys Sci., 6(14): 353950. DOI: $10.5897 /$ IJPS11.272

3. Tara Chand V., Ravi Sankar B. and RangarayaChowdary J., 2013. Exergy Analysis of Gas Turbine Power Plant, International Journal of Engineering Trends and Technology, 4(9): 3991-3993.

4. Naga Bhushana Rao V, Niranjan Kumar I N and Bala Prasad K, 2014. Failure Analysis of Gas Turbine Blades in a Gas Turbine Engine Used For Marine Applications, Int. J. of Engineering, Science and Technology, 6 (1): 43-48.

5. Naga Bhushana Rao V, Niranjan Kumar I N, Madhulata N and Abhijeet A, 2014. Mechanical Analysis of 1st Stage Marine Gas Turbine Blade, International Journal of Advanced Science and Technology, 68: 57-64.

6. Naga Bhushana Rao V., Niranjan Kumar I.N., Bala Prasad K., Madhulata N. and Naresh Gurajarapu, 2014. Failure Modes/Mechanisms in Turbine Blades of a Gas Turbine Engine -An Overview, International Journal of Engineering Research and Development, 10: 48-57.

7. J. F. Louis, K. Hiraoka and M. A. El Masri, 1983. A Comparative Study of the Influence of Different Means of Turbine Cooling on Gas Turbine Performance, ASME Paper No. 83-GT-180.

8. Singh, Onkar, and B. N. Prasad. "Influence of different means of turbine blade cooling on the thermodynamic performance of combined cycle." Applied Thermal Engineering 28, no. 17-18 (2008): 2315-2326.

9. M.A. El-Masri, 1986. On Thermodynamic of Gas Turbines Cycle - Part-2 - A Model for Expansion in 
Cooled Turbines, J. Eng. Gas Turbines Power, 108 (1): 151-159. doi:10.1115/1.3239862

10. M.A. El-Masri, 1988. GASCAN-An Interactive Code for Thermal Analysis of Gas Turbine Systems, J. Eng. Gas Turbines Power, 110(2): 201-209. doi:10.1115/1.3240104

11. O. Bolland and J.F. Stadaas, 1995. Comparative Evaluation of Combined Cycles and Gas Turbine Systems With Water Injection, Steam Injection, And Recuperation, J. Eng. Gas Turbines Power, 117(1): 138-145. doi:10.1115/1.2812762

12. Sanjay, Onkar Singh and B.N. Prasad, 2008. Influence of Different Means of Turbine Blade Cooling on The Thermodynamic Performance of Combined Cycle, Appl. Therm Eng., 28: 2315-2326. doi.org/10.1016/j.applthermaleng.2008.01.022

13. Sanjay Kumar and Onkar Singh, 2013. Performance Evaluation of Gas-Steam Combined Cycle Having Transpiration Cooled Gas Turbine, Distributed Generation \& Alternative Energy Journal, 28(2): 43-60. doi: 10.1080/21563306.2013.10677550

14. Bassily A.M., 2013. Modeling, Analysis, and Modifications of Different GT Cooling Techniques For Modern Commercial Combined Cycle Power Plants With Reducing The Irreversibility of The HRSG, ApplTherm Eng., 53(1): 131-146. doi.org/10.1016/j.applthermaleng.2013.01.002

15. Jury Polezhaev, 1997. The Transpiration Cooling For Blades of High Temperatures Gas Turbine, Energy Conversionand Management, 38: 1123-1133. doi.org/10.1016/S0196-8904(96)00142-2

16. Facchini B., 1999. Cooled Expansion in Gas Turbines: A Comparison of Analysis Methods, Energy Conversionand Management, 40(11): 1207-1224. doi.org/10.1016/S01968904(99)00003-5

17. Bruno Facchini, Giovanni Ferrara and Luca Innocenti, 2000. Blade Cooling Improvement For Heavy Duty Gas Turbine: The Air Coolant Temperature Reduction and The
Introduction of Steam and Mixed Steam/Air Cooling, International Journal of Thermal Sciences, 39(1): 74-84. doi.org/10.1016/S1290-0729(00)00194-X

18. Mohammad H. Albeirutty, Abdullah S. Alghamdi and Yousef S.Najjar, 2004. Heat Transfer Analysis For A Multistage Gas Turbine Using Different Blade-Cooling Schemes, Applied Thermal Engineering, 24(4): 563-577.

19. Yousef S.H Najjar, Abdullah S Alghamdi and Mohammad H Al-Beirutty, 2004. Comparative Performance of Combined Gas Turbine Systems Under Three Different Blade Cooling Schemes, Applied Thermal Engineering, 24(13):1919-1934.

20. Harlock J. H., 2000. The Basic Thermodynamics of Turbine Cooling, J. Turbomach, 123(3): 583-592. doi:10.1115/1.1370156

21. Horlock J. H., Watson D. T., and Jones T. V., 2001. Limitation on Gas Turbines Performance Imposed by Large Turbine Cooling Flows, J. Eng. Gas Turbines Power, 123(3): 487-494. doi:10.1115/1.1373398

22. J.P. Yadav and O. Singh, 2000. Thermodynamic Analysis of Air Cooled Simple Gas/Steam Combined Cycle Plant. IE(I) Journal MC.2000, 86: 217-222

23. Meeta Sharma and Onkar Singh, 2017. Investigations for performance enhancement of dual pressure HRSG in gas/steam combined cycle power plants, International Journal of Ambient Energy, 38(4): 339-346. doi:10.1080/01430750.2015.1100680

24. Abdul GhafoorMemon, Rizwan Ahmed Memon, KhanjiHarijan and Muhammad Aslam Uqaili, 2014. Thermo-environmental analysis of an open cycle gas turbine power plant with regression modeling and optimization, Journal of Energy Institute, 87(5): 81-88. doi: 10.1016/j.joei.2014.03.023

25. Kristin Jordal, Olav Bollard and Ake Klang, 2004. Aspects of Cooled Gas Turbine Modeling for the Semi-Closed O2/CO2 Cycle With CO2 Capture, Journal of Engineering for Gas Turbines and Power, 126(3): 507-515.

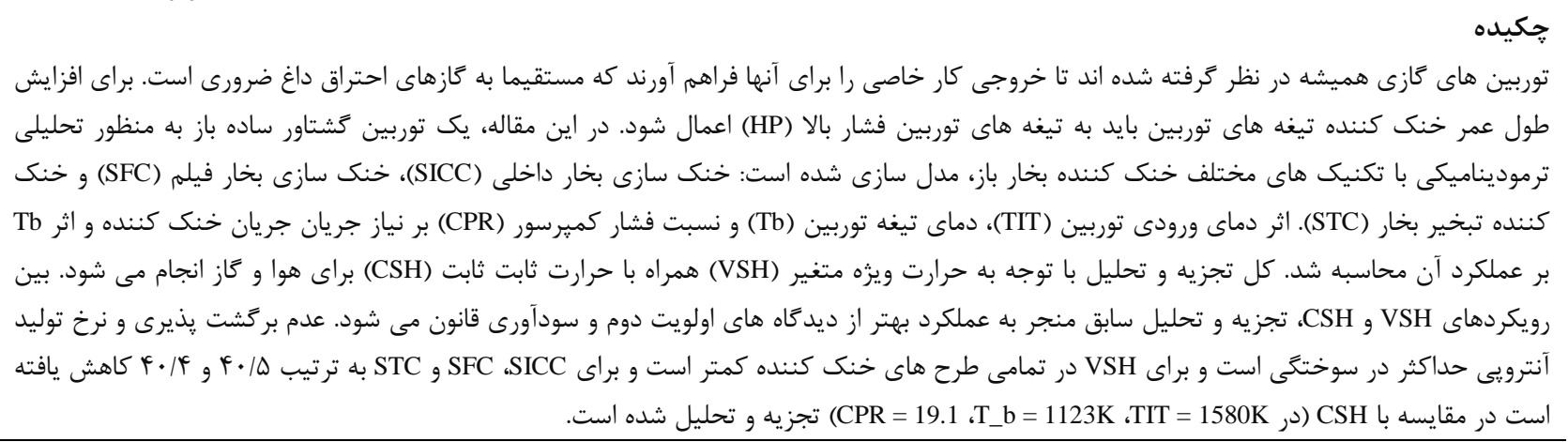

